\title{
Treatment of Affixes in Four English Advanced Learner's Dictionaries
}

\author{
Yan Chen ${ }^{1}$ \\ ${ }^{1}$ Department of English Education, School of Foreign Languages, Yancheng Teachers University, Yancheng, \\ Jiangsu, China \\ Correspondence: Yan Chen, Department of English Education, School of Foreign Languages, Yancheng \\ Teachers University, Yancheng, Jiangsu, China.
}

\author{
Received: September 2, 2018 Accepted: October 2, 2018 Online Published: November 28, 2018 \\ doi:10.5539/ells.v8n4p38 URL: https://doi.org/10.5539/ells.v8n4p38
}

\begin{abstract}
The paper is a close examination of the treatment of affixes in the latest print versions of four English advanced learner's dictionaries, i.e., $O A L D 9, L D O C E 6, C O B U I D 8$, and $C A L D 4$, at both macrostructure and microstructure levels. Through comparison and contrast, the author has produced some major findings. Firstly, special sections on affixes are a desirable supplement to prevalent alphabetical listing of affixes in the A-Z text. Secondly, forms for presentation of affixes include specification of the part of speech of the root with which an affix can be combined and indication of the part of speech of the derivative thus formed. Thirdly, cross-references help to establish the semantic relations between affixes like variant spellings, allomorphs, and synonymous affixes. Finally, more research needs to be done on lexicographical representation of affixes, especially on the wise use of space and on the proper establishment of relations between affixes.
\end{abstract}

Keywords: affixes, special sections, arrangement, forms of presentation, sense relations

\section{Introduction}

In the analysis of linguistic units, morphemes are usually divided into two sub-categories: free morphemes which can stand alone as words, and bound morphemes which can only be meaningful or functional as parts of words. Bound morphemes often manifest themselves as prefixes or as suffixes, which are collectively called affixes (see for example, Singleton, 2000, p. 34). The fact that the number of formations resulted from affixation is almost unrestricted has made it impossible for any dictionary to include all such formations, and the necessity of listing affixes as headwords in the dictionary has long been recognized by lexicographers (e.g., Murray, 1888, p. ix, quoted in Kastovsky, 2000, p. 114; Zgusta, 1971, pp. 241-242; Stein, 1985, p. 37; Svensén, 1993, p. 43, 67; Atkins \& Rundell, 2008, p. 165). The $O E D$, for instance, has listed some affixes in separate entries with etymological information, definitions, examples and corresponding quotations, and dealt with others in separate articles, but not without problems (For more detail, see Kastovsky, 2000, p. 123).

So far, the inclusion of affixes in dictionaries is prevalent, then the lexicographic treatment of affixes comes into focus: How are affixes treated in dictionaries? A careful search in books and magazines on lexicography for relevant literature has produced few findings. In other words, little research has been conducted on the treatment of affixes in dictionaries of various types. As far as general dictionaries are concerned, Stein (1985) is among the first scholars to make a relatively thorough study of affix treatment in dictionaries; she focuses on lexicographical problems of word-formation processes like compounding and affixation, and points out that lexicographical treatment of word formation is closely related to the development of lexicology. Mettinger (1990, pp. 93-112), by examining the treatment of $u n$-formations in two monolingual dictionaries of contemporary English, i.e., $C O E D$ and $A L D$, has found the structure of the respective entries unsystematic. Kastovsky (2000, pp. 110-125) has taken a close look at the entries for prefixes and suffixes in the $O E D$ and found a problem caused by the strict adherence to the etymological principle, as is shown the entry for the prefix re-: while some examples can be interpreted as containing re- in the sense of "again" (e.g., re- in rearrange, reignite), other examples (e.g., re- in recluse, relic) would not have been analysable into a prefix and a base at the time of borrowing so that it would not have been possible to extract a living prefix from them, thus constituting an element that originated as a prefix at some time in history but can no longer be regarded as a meaningful element in the lexical items in question. These researches may lead to the conclusion that treatment of affixes in general dictionaries is far from satisfactory. 
As far as the treatment of affixes in learner's dictionaries is concerned, Herbst (1996, pp. 351-353) has found two rivaling principles for the arrangement of compounds and derivatives, i.e., a purely alphabetical listing and a more semantically motivated organization, and discussed their respective advantages and disadvantages, but he has made no mention of the treatment of affixes. Hacken, Abel and Knapp (2006) have found that the treatment of word formation in existing learner's dictionaries does not support the acquisition of word formation rules in a way that would help the learner's expansion of vocabulary and has elaborated on an electronic German and Italian learner's dictionary optimizing the support for the acquisition of word formation. With respect to the treatment of affixes in the print learner's dictionary, nothing has been found, which renders a probe into the issue both necessary and urgent.

\section{Research Question and Methods}

In English teaching and learning, affixes have been regarded as of great importance. The strategy of instruction in affixes in language teaching and learning has been advocated by, for example, Baumann, Font, Edwards, and Boland (2005), Allen (2002, p. 96), Nation (2004. pp. 168-171). In view of the great popularity of advanced learner's dictionaries among foreign learners of English, the present author attempts to answer one research question:

How are affixes treated in the latest print versions of English advanced learner's dictionaries?

To provide a useful answer to this question, the author needs to examine affixes at both macrostructure and microstructure levels of dictionaries, to reveal the policies lexicographers have followed as regards affixes, as well as the strengths and weaknesses of each policy. The data will be gathered from the latest print versions of four most reputable English advanced learner's dictionaries, i.e., Oxford Advanced Learner's Dictionary (2016, $9^{\text {th }}$ edition, hereafter $\left.O A L D 9\right)$, Longman Dictionary of Contemporary English for Advanced Learners $\left(2014,6^{\text {th }}\right.$ edition, hereafter LDOCE6), Collins COBUILD Advanced Learner's Dictionary (2014, new $8^{\text {th }}$ edition, hereafter COBUILD8), and Cambridge Advanced Learner's Dictionary (2013, $4^{\text {th }}$ edition, hereafter CALD4).

The methods to be used for the research include case studies, comparison and contrast. The study of specific affix entries may demonstrate characteristics of lexicographic representation of affixes, whereas comparison and contrast of those entries may help to reveal the respective advantages and disadvantages of a particular policy. All the data will be analyzed in view of lexicological and lexicographical principles. A thorough exploration of affix treatment in the dictionaries under study, the author hopes, will contribute to the perfection of affix treatment in future English advanced learner's dictionaries.

\section{Treatment of Affixes at the Macrostructure Level}

The macrostructure refers to "the overall list structure which allows for the compiler and the user to locate information in a reference work" (Hartmann and James, 1998, p. 91). Common formats in Western dictionaries include the alphabetical word-list, thematic ordering, chronological ordering, and ordering by frequency, which can be supplemented by the front matter, middle matter or back matter in the dictionaries.

\subsection{Special Sections on Affixes}

The four dictionaries show two different policies as to whether a special section is provided for a brief discussion of affixes. CALD4 contains no special sections concerning affixes at all. OALD9 does mention affixes in the back matter, but not in the form of a special section: a short paragraph in "Using the dictionary - a detailed guide to the entries" stating that affixes are listed as headwords, that the classes of words they can be attached to are indicated, and that definitions are supplied and examples of the derivatives given, together with two lists in the "More like this" section, i.e., a list of 36 prefixes and a list of 36 suffixes, both lists having nothing more than the affixes themselves. $L D O C E 6$ and COBUILD 8 offer special sections, but with some differences.

In $L D O C E 6$, a section entitled "Word Formation" in the back matter is devoted to a very brief introduction (2 pages in total) to prefixes and suffixes. It makes it clear that prefixes and suffixes can be added to a word to change its meaning or word class. The most common ones, like -ize, -er, and the four allomorphs un-, in-, -im, -il, -ir as a group, are shown in blue-colored boxes, each with example words on both sides in the box and one example sentence below the box, to show how they are used in the process of word formation. It is interesting to note that suffixes are grouped under four subtitles, including "verb formation", "noun formation", "adverb formation", and "adjective formation", probably because suffixes mainly change the word classes of the roots. In contrast, only one subtitle, i.e., "opposites", is given for prefixes which can be used in front of many words to produce an opposite meaning, including un-, in-, dis-, and de-. The title of this special section is somewhat misleading in that word formation means much more than making new words with prefixes and suffixes; processes like compounding, conversion, blending, clipping, back-formation are all important word-building 
processes.

In COBUILD8, an independent section entitled "Prefixes and suffixes" in the introduction first explains what a prefix or suffix is and how they function in word formation, and then offers two subsections entitled "Prefixes" and "Suffixes" respectively, where the most frequent prefixes and suffixes are listed, each in an entry with at least one example word put in a sentence which explains its meaning, as is shown in the following example:

mini- forms nouns which refer to units which are a smaller version of something else. For example, a minibus is a small bus.

To be more exact, the section in COBUILD8 exhibits four features. First, prefixes and suffixes, e.g., eco-, non-, sub-, -al, and -ic, are listed in separate entries. Secondly, polysemous prefixes and suffixes, e.g., bi-, extra-, -ish, and $\mathbf{- y}$, are given separate entries to deal with their different meaning and usage. Thirdly, allomorphs are listed in one entry, e.g., il-, im-, in-, ir- as a group in the entry beginning with -il; -ation, -ication, -sion, -tion as another group in the entry beginning with -ation. In some cases, some allomorphs are not only treated in one entry, but also cross-referenced. For example, -ability and -ibility are treated in the entry beginning with -ability, but in the -ibility entry, "see -ability" points the user to -ability. The same is true with -ance and -ence, -er and -or. On the whole, the four-and-a-half-page section may as well function as a mini-dictionary for the most frequent prefixes and suffixes, which enables the user to have a general picture of the highly productive affixes in a few pages and hasten the process of getting to know part of the meaning of many more words containing the affixes.

In summary, special sections on affixes define prefixes and suffixes, state their functions in word creation, and exemplify the usage of them in example words and sentences. Sketchy as they may appear as against discussions of affixes in works on lexicology, they enable users to understand the basic characteristics of such linguistic elements and serve as a useful guide for further exploration of and supplement to affixes treated in the A-Z text. On the contrary, OALD 9 and CALD4, in which no or no truly special sections exist, deny the learner an opportunity to build up a picture of productive affixes that are greatly beneficial to their vocabulary expansion.

\subsection{The Arrangement of Prefixes and Suffixes in the A-Z Text}

In the four dictionaries, the list of headwords is ordered alphabetically, which may pose no problems for free morphemes. However, for bound morphemes like prefixes and suffixes, problems do arise. Take for example a homophonic pair: en- vs. -en. In OALD9, LDOCE6, and CALD4, the entry for en- is located before that for -en, but in COBUILD8, only en- is selected as a headword, but not -en. The treatment of another pair, in- vs. -in, is more diversified. While CALD4 puts the entry for -in before that for in-, OALD9 puts the in- entry before the -in entry but treats the latter as a "combining form" rather than a suffix. The other two dictionaries have not included -in at all. In this case, two questions need to be raised:

1) Should there be a fixed order for homophonic affix pairs, for instance, prefix first and suffix second, or vice verse?

2) What are the criteria for the inclusion of affixes?

The first question might not be that serious as the homophonic pairs are close by so that they pose no difficulties for users to retrieve. That said, lexicographers, in this case those of CALD4, should be consistent in the ordering of homophonic pairs, rather than arrange them arbitrarily.

The second question may lead to various answers. As the four dictionaries are based on corpus data, we would expect that there would be a lot of similarity in the affixes selected. In the case of highly productive affixes, like anti-, en-, micro-, -ful, -ist, -ly, the four unanimously select them. However, a lot of other affixes are not included in all the four but vary from dictionary to dictionary. For instance, a- is not included in CALD4 but in the other three, -ess is found in OALD9 and LDOCE6, but not in the other two dictionaries. This does not come as a surprise, as no two dictionaries would have the same headword list. Such differences in the selection of affixes might have appeared for two reasons: the different coverage of the corpus data on which each individual dictionary is based, and the anatomy of affixes by the lexicographers when they dealt with raw data. The latter explanation is supported by the above-mentioned case of -in. CALD4 lists -in as a suffix and exemplifies it with sit-in and phone-in, while OALD9 lists it as a "combining form" which in its dictionary entry is defined as "a form of a word that can combine with another word or another combining form to make a new word, for example techno- and -phobe in technophobe". The other two dictionaries have given phone-in and sit-in headword status, but not -in, which might have resulted from the lexicographers' varied opinions on whether -in is a suffix or not. In other words, the difference in the inclusion or omission of some affixes reflect, to some extent, the dictionary makers' differing understanding of what constitutes a suffix.

$O A L D 9$ 's use of the term "combining form" points to a problem concerning the use of terminologies and their 
lexicographical representation. While $O A L D 9$ treats both techno- and -phobe as combing forms, the other three dictionaries treat them as prefix and suffix respectively. Then a question seems appropriate: is the term "combining form" necessary when the terms "prefix" and "suffix" can account for the specific functions of affixes more clearly?

One last problem with treatment of affixes at the macrostructure level is found in COBUILD9. A special design of COBUILD9, "Word Link", is created to "increase language awareness by showing how words are built in English" (Guide to key features, p.ix), with a focus on prefixes, suffixes, and word roots. The word link sections are inserted in the A-Z text both alphabetically and in relation to an entry for a free morpheme containing a prefix, suffix, or word roots. Linguistic elements such as -let, cred, centr, cracy, merit, suad, suas are put into colored boxes with a simple definition and three examples of it appearing in a word. For instance, right above the entry for booklet, there is a box as follows:

\section{Word Link let = little: booklet, coverlet, droplet}

The same box appears again above the entry for coverlet and booklet, but nowhere else in the whole dictionary; nor is -let given a headword status. The learner would have no way to know how to find the word link if he or she is trying to decipher piglet or starlet. The repetition and positioning of the box is both a waste of space and a detriment to the accessibility of the link.

\section{Treatment of Affixes at the Microstructure Level}

The microstructure, i.e., the internal design of a reference unit, provides detailed information about the headword, with comments on such formal and semantic properties as spelling, pronunciation, grammar, definition, usage, and etymology (Hartmann and James, 1998, p. 94).

\subsection{Forms of Presentation of Affixes}

In the four dictionaries, affixes are generally treated in the same way as free morphemes and provided with largely the same categories of information. Entries for affixes usually contain such information categories as pronunciation, variant spelling if there is any, role (prefix or suffix), and definition, the latter of which is usually described and exemplified, as is shown in the following examples:

Table 1. Categories of information about affixes in the learner's dictionaries

\begin{tabular}{|c|c|c|}
\hline Dictionary & Affix & Entry \\
\hline \multirow[t]{2}{*}{ OALD9 } & Prefix & $\begin{array}{l}\text { re- /ri:/ prefix (in verbs and related nouns, adjectives and adverbs) again: reapply } \diamond \\
\text { reincarnation } \diamond \text { reassuring }\end{array}$ \\
\hline & Suffix & -ness suffix (in nouns) the quality, state or character of: dryness $\diamond$ blindness $\diamond$ silliness... \\
\hline \multirow[t]{2}{*}{ CALD4 } & Prefix & $\begin{array}{l}\text { re- /ri:/,/ri/, /rI/ prefix } 1 \text { used to add the meaning 'do again', especially to verbs: rebuild } \circ \\
\text { remarry } \circ \text { reusable } 2 \text { returning something to its original state: reafforestation (= planting new trees } \\
\text { in an area where they were previously cut down) }\end{array}$ \\
\hline & Suffix & $\begin{array}{l}\text {-ness /-nəs/ suffix added to adjectives to form nouns which refer to a quality or a condition: } \\
\text { happiness } \circ \text { sadness } \circ \text { nervousness } \circ \text { selfishness } \circ \text { kindness }\end{array}$ \\
\hline
\end{tabular}

The above example entries show forms of presentation which are particular to affixes: specification of the part of speech of the root with which an affix can be combined, and indication of the part of speech of the derivative thus produced. Unlike the treatment of free morphemes as headwords, no simple grammatical labels such as $n$, $v$., $a d v$. are inserted before the description of the usage and meaning of the affixes, but the wording in the description shows word-formation processes (i.e., prefixation, suffixation), which fulfills both decoding and encoding functions for the active learner. The learner is given not only access to the meaning and grammatical property of the affixes in some existing words, but also an opportunity to learn to use the affixes to create new or nounce words in the future.

Sometimes, restrictive labels or explanations are exploited to show the special features of some affixes, including affective labels (e.g., approval) to show connotations, style labels (e.g., spoken) to specify levels of formality, and regional labels (e.g., Brit., UK, US) to mark the spelling or pronunciation, as can be seen in the following examples: 
Table 2. Restrictive labels for affixes in the learner's dictionaries

\begin{tabular}{|c|c|}
\hline Dictionary & Entry \\
\hline OALD9 & -ish ... 2 (sometimes disapproving) having the nature of, like... \\
\hline LDOCE6 & $\begin{array}{l}\text {-ish ... } 4 \text { [in adjectives] the ending of some adjectives that show disapproval: selfish... } 6 \text { [in adjectives] } \\
\text { spoken APPROXIMATELY: We'll expect you around eightish (=at about eight o'clock). | He's fortyish } \\
\text { (=about } 40 \text { years old). }\end{array}$ \\
\hline COBUILD 8 & -ize /-aiz/ (-izes, -izing, -ized) in BRIT, also use -ise ... \\
\hline CALD4 & $\begin{array}{l}\text {-ize (UK usually -ise) /-aiz/ suffix } \ldots \\
\text {-ability /-ə.bIl.I.ti/us /-ə.ti/s suffix... }\end{array}$ \\
\hline
\end{tabular}

With respect to definition, $O A L D 9, L D O C E 6$ and $C A L D 4$ maintain the traditional format of definitions as phrases where nouns are defined by noun phrases, verbs by verbal phrases. However, COBUILD 8 has kept its tradition of definitions in complete sentences, e.g.,

-ness/ -nəs / SUFFIX -ness is added to adjectives to form nouns which often refer to a state or quality. For example, 'sadness' is the state of being sad and 'kindness' is the quality of being kind. ' 'This is not good,' he said with great seriousness.

As in the other three dictionaries, vocabulary items containing the affix are cited to further explain and support the definition, but COBUILD8 provides extra information by incorporating sentences containing the affix in question. In this case, two issues may arise. Firstly, for a reader, the sentence definition could be a negative feature, since he or she has to extract information from a setting that is not always relevant to him or her (Bogaards, 1996, p. 292). Secondly, considering that the sentence definition of the affix is explicit enough and the example words sadness and kindness are supportive enough, the sentence example contributes little to the clarification of the affix, thus constituting more or less a waste of space.

\subsection{Establishment of Sense Relations Between Affixes}

\subsubsection{Treatment of Suffix Combinations}

Suffix combinations contain more than one suffix, e.g., -ably $<$-able + -ly $>$, -lessness $<$-less + -ness $>$. OALD 9 and LDOCE6 includes suffix combinations in the entry for the first suffix, e.g.,

Table 3. Treatment of suffix combinations in the learner's dictionaries

\begin{tabular}{ll}
\hline Dictionary & Entry \\
\hline OALD9 & -less /-ləs / suffix (in adjectives) 1 without: treeless $\diamond$ meaningless 2 not doing; not affected by: tireless $\diamond$ \\
& selfless $\bullet$-lessly (in adverbs): hopelessly -lessness (in nouns): helplessness... \\
\hline LDOCE6 & -able /əbəl/ (also -ble) suffix [in adjectives] 1 that you can do something to: washable (=it can be washes) | \\
& $\begin{array}{l}\text { unbreakable (=it cannot be broken) } \quad \text { loveable (=easy to love) } 2 \text { having a particular quality or condition: } \\
\text { knowledgeable (=knowing a lot) } \mid \text { comfortable - -ably / oboli/, -ibly suffix [in adverbs]: unbelievably }\end{array}$ \\
\hline
\end{tabular}

It can be seen that the two dictionaries follow the same policy: treating the suffix combinations as undefined but exemplified run-on entries. This not only gives the learner an opportunity to know more affixes and their usage, but also saves more space than if the combinations are treated separately. In cases where OALD9 and LDOCE6 offer such run-ons, COBUILD 8 and CALD4 include none of the combinations. One explanation for such absence might be that the component suffixes are included as headwords already so that the learner might figure out the overall meaning and usage of the combinations. However, as some adverbs are formed through an intermediate stage of an adjective, which might involve some change in the spelling not easily recognizable to the learner, for instance, arguably from argue+-able+-ly, it would be of great convenience for the learner to identify the semantic relatedness of the suffixes if the combinations are included in one entry.

\subsubsection{Cross-references for Allomorphs and Synonymous Affixes}

A cross-reference is "a word or symbol in a reference work to facilitate access to related information" (Hartmann and James, 1998, p. 32). Cross-references are of great importance in dictionaries for they help to set up a network of relations that exist between different information categories or data. With the help of cross-references, the learner may be able to see the relationships between lexical items that are obscured by strict adherence to an alphabetical ordering of headwords. 
In the four dictionaries, allomorphs like -ize/-ise, -ance/-ence, -able/-ible are usually listed, but treated differently in terms of cross-references. The devices used for the purpose include the right-pointing arrow and verbal indication. The former device is used by $O A L D 9$ and $C O B U I L D 8$, e.g.,

Table 4. The right-pointing arrow as a device for cross-referencing in the learner's dictionaries

\begin{tabular}{ll}
\hline Dictionary & Entry \\
\hline OALD9 & -ance, -ence suffix (in nouns) the action or state of: assistance, confidence... \\
& -ence $\rightarrow$-ANCE \\
\hline COBUILD8 & -ize /-aiz/ (-izes, -izing, -ized) in BRIT, also use -ise SUFFIX Verbs that can end in either '-ize' or '-ise' \\
& are dealt with in this dictionary at the '-ize' spelling. Many verbs ending in -ize describe processes by \\
& which things or people are brought into a new state. $\square$ The dispute could jeopardize the negotiations. $\square . . . a$ \\
& way of trying to regularize ad standardize practice. \\
& -ise /aize/ $\rightarrow$ see -ize
\end{tabular}

The arrow refers the learner to the entry for the other allomorph without taking up much space, but the disadvantage is that the learner would have to look up the entry referred to before he can find the more detailed information. In contrast, verbal indication lacks visual vividness, as is shown in the following:

Table 5. Verbal indication as a device for cross-referencing in the learner's dictionaries

\begin{tabular}{ll}
\hline Dictionary & Entry \\
\hline LDOCE6 & -ance /ons/, -ence suffix [in nouns] the action, state, or quality of doing something or of being something: his \\
& sudden appearance (=he appeared suddenly) | her brilliance (=she is BRILLIANT) \\
& -ence / ons / suffix [in nouns] another form of the suffix -ANCE: existence | occurrence \\
\hline CALD4 & -ance $/$ - $^{\circ} \mathrm{ns} /$ suffix -ence \\
& -ence (also -ance) $/{ }^{\circ} \mathrm{ns} /$ suffix ACTION $\triangleright 1$ used to form nouns which refer to an action or series of \\
& actions: violence (=violent actions) $\circ$ a performance (=act of performing) $\triangleright$ STATE 2 used to form nouns \\
& which describe a state or quality: her long absence (=period during which she was absent)
\end{tabular}

Anyhow, the inclusion of the allomorph in each entry does show the learner the semantic relation between the headwords. Whichever device a dictionary uses, the active learner may get to know that relation. Unfortunately, careless omission of cross-references is found in CALD4, e.g.,

-ability /-ə.bIl.I.ti/us /-ə.ti/ suffix (also -ibility) used to form nouns from adjectives ending in '-able' or '-ible', to mean the quality of being the stated adjective: suitability $\circ$ stability

-ibility /-I.bIl.I.ti/ us /-o.ti/ suffix used to form nouns from adjectives ending '-ible' or 'able': accessibility

In neither of the entries can we find a cross-reference. This omission might seem unimportant as the information in each entry is quite abundant, but the failure in cross-referencing deprives the learner of a good opportunity to link the two suffixes both in form and in meaning.

As for the cross-reference for synonymous affixes, $C A L D 4$ is the only one among the four dictionaries to provide a link, e.g.,

in- (before $\mid$ il-, before $b, \mathrm{~m}$ or $\mathrm{p}$ im-, before $\mathrm{r}$ ir-) prefix used to add the meaning 'not', 'lacking', or 'the opposite of' to adjectives and to words formed from adjectives: incompletelincompletely o illegal/illegally $\circ$ impossible/impossibly $\circ \quad$ irregular/irregularly $\rightarrow$ Compare dis-, non-, un-

The right-pointing arrow followed by the word "compare" reminds the learner to pay attention to the relationship among these affixes, but unfortunately the three allomorphs il-, im-, and ir- are not listed as headwords at all, which represents a second kind of omission in CALD4, much to the disadvantage of the learner.

\section{Conclusion}

In order to develop a multi-dimensional view of affixes, the learner needs to be made aware of various properties concerning their form and meaning: spelling, pronunciation and stress, part of speech and that of the roots they combine with, definition, restrictions in usage if there is any, and sense relations with other affixes in some cases. This close examination of the four dictionaries has produced some major findings: Firstly, special sections on affixes are a desirable supplement to prevalent alphabetical listing of affixes in the A-Z text in that they provide 
starting points for the learner to know highly productive affixes in a few pages. Secondly, affixes are presented at the microstructure level in ways particular to the treatment of affixes: specification of the part of speech of the root with which an affix can be combined and that of the derivative thus produced, but the treatment of specific affixes is problematic in some dictionaries in terms of space, accessibility and usefulness. Thirdly, cross-references are used to establish the semantic relations between affix families, allomorphs, and synonymous affixes, but inadequacies are also found. Finally, more research needs to be done on the terminologies for lexicographical representation of affixes, on the wise use of space, and on the devices for establishment of relations between affixes.

\section{Acknowledgements}

A research project supported by Yancheng Teachers University under Grant 12YSYJB0105, and by Education Department of Jiangsu Province and Finance Department of Jiangsu Province under Grant Top-notch Academic Programs Project of Jiangsu Higher Education Institutions.

\section{References}

Allen, V. F. (2002). Techniques in Teaching Vocabulary. Shanghai: Shanghai Foreign Language Education Press.

Atkins, B. T., \& Rundell, Michael. (2008). The Oxford Guide to Practical Lexicography. Oxford: Oxford University Press.

Baumann, J. F., Font, G., Edwards, E., \& Boland, E. (2005). Strategies for teaching middle-grade students to use word-part and context clues to expand reading vocabulary. In E. H. Hiebert \& M. L. Kamil (Eds.), Teaching and Learning Vocabulary: Bring Research to Practice (pp. 179-206). London: Lawrence Erlbaum Associates, Publishers.

Bogaards, P. (1996). Dictionaries for learners of English, International Journal of Lexicography, 9(4), 277-320. https://dx.doi.org/10.1093/ijl/9.4.277

Fox, C., \& Combley, R. (2014). Longman Dictionary of Contemporary English for Advanced Learners (6th ed., LDOCE6). Harlow: Pearson Education Limited.

Hacken, P., Abel, A., \& Knapp, J. (2006). Word formation in an electronic learners' dictionary: ELDIT. International Journal of Lexicography, 19(3), 243-256.

Hartmann, R. R. K., \& James, G. (1998). Dictionary of Lexicography. London: Routledge. https://dx.doi.org/10.4324/9780203159040

Herbst, T. (1996). On the way to the perfect learners' dictionary: a first comparison of OALD5, LDOCE3, COBUILD2 and CIDE. International Journal of Lexicography, 9(4), 321-357.

Hornby, A. S. (2016). Oxford Advanced Learner's Dictionary (9th ed., OALD9). Oxford: Oxford University Press.

Kastovsky, D. (2000.) Words and word-formation: Morphology in OED. In L. Mugglestone (Ed.), Lexicography and the OED, Pioneers in the Untrodden Forest (pp. 110-125). Oxford: Oxford University Press.

McIntosh, C. (2013). Cambridge Advanced Learner's Dictionary (4th ed., CALD4). Cambriddge: Oxford University Press.

Mettinger, A. (1990). Oppositeness of meaning, word-formation, and lexicography: the English prefix un-. In J. Tomaszczyk \& B. Lewandowska-Tomaszczyk (Eds.), Meaning and Lexicography (pp. 92-112). Amsterdam: John Benjamins. https://dx.doi.org/10.1075/llsee.28.12met

Nation, I. S. P. (2004). Teaching and Learning Vocabulary. Beijing: Foreign Language Teaching and Research Press. https://dx.doi.org/10.1016/0346-251X(94)90065-5

Sinclair, J. (2014). Collins COBUILD Advanced Learner's Dictionary (New 8th ed., COBUILD8). Glasgow: HarperCollins Publishers.

Singleton, D. (2000). Language and the Lexicon: An Introduction. London: Arnold. https://dx.doi.org/10.4324/9781315824796

Stein, G. (1985). Word-formation in modern English dictionaries. In Robert Ilson (Ed.), Dictionaries, Lexicography and Language Learning (pp. 35-44). Oxford: Pergamon.

Svensén, B. (1993). Practical Lexicography: Principles and Methods of Dictionary-Making. Oxford: Oxford University Press. 
Zgusta, L. (1971). Manual of Lexicography. Mouton: The Hague. https://dx.doi.org/10.1515/9783111349183

\section{Copyrights}

Copyright for this article is retained by the author, with first publication rights granted to the journal.

This is an open-access article distributed under the terms and conditions of the Creative Commons Attribution license (http://creativecommons.org/licenses/by/4.0/). 